the rights we currently enjoy. Oppressive regimes typically stifle enquiry, as critical minds will inevitably also scrutinize their leaders. Enquiry is further undermined in such environments by the award of senior academic posts to the politically loyal rather than the competent, and the selection of policies or actions that suit governments' agendas, regardless of the scientific evidence.

That latter characteristic is central to the trial of six medical workers - five Bulgarian nurses and a Palestinian doctor - currently facing the death penalty in Libya on charges of infecting hundreds of children with HIV (see page 612). The real evidence has been purged from the trial. So it is encouraging that several major scientific bodies have now weighed in to demand that the court hears the scientific facts.

Tripoli may seem far away, but knowledge and academic freedom are central planks in many other struggles across the world for more open, democratic societies. Academics and universities are often hotbeds of such reform movements, and every year hundreds of academics worldwide consequently face threats, or worse. It is important that we do not forget them.

Many learned societies, including the American Physical Society and the American Chemical Society, as well as several scientific academies, have human-rights committees that play an active role in defending individuals at risk. This diverse range, and the mechanism whereby one body takes the lead on a case where it knows the community, is an effective way of dividing up resources. Cases are many, and no one community can give sustained attention to them all.

Most societies' human-rights activities are run on a shoestring by volunteers. The US National Academies' Committee on Human Rights is among the most effective, and has a full-time secretariat. Yet it runs on a budget of just $\$ 0.5$ million a year, most of it contributed by philanthropies. Scientists must find the means to better fund and professionalize such activities.

Often these committees use political contacts and letter-writing campaigns to try to influence the outcome of particular cases. At the very least, this serves to remind perpetrators that they are under international scrutiny. Scientists who have been freed testify that, although difficult to pin down, such support is crucial. All scientists can contribute, by making themselves aware of current cases of human-rights abuses and by lending their support to campaigns against them.

\section{Ambassador for Earth}

\section{Is it time for SETI to reach out to the stars?}

$(2$ ne of the strengths of the community involved in the search for extraterrestrial intelligence - known as SETI - is its imaginative capacity to take seriously things that most people dismiss out of hand.

The idea that the technologies of astronomy might go beyond allowing us new insights into the natural world, and provide us with a means of communion with alien creatures, is not entirely fanciful. Artificial phenomena, such as civilizations, will radiate energy as surely as natural ones do - and may even do so with the intention of communicating. We on Earth send a mish-mash of unnaturallooking radio waves out into the cosmos, not to mention a handful of neutrino beams.

But what if we were to add to that mish-mash some deliberate signals? If beamed tightly enough with the help of a radio-telescope antenna, even a low-power radio transmission can stand out from the general murmur to a star where it is aimed. This is the idea behind so-called 'active SETI', which some enthusiasts think is a way forward for the field. There are others who think that it poses small but real dangers, and thus needs to be discussed more broadly. But at a recent meeting of the International Academy of Astronautics SETI study group in Valencia, Spain, the mood of the gathering was with the enthusiasts.

It is easy to see the appeal of active SETI - it's right there in the adjective. Traditional SETI involves looking at vast amounts of radio data and finding nothing. Active SETI allows you to compose messages, pick target stars, develop new encodings, and so on. It can be used as an outreach tool - the European television channel Arte is currently encouraging people to send it messages specifically to be beamed to the stars as part of the celebrations surrounding the launch of Corot, a French satellite designed to detect planets around distant stars.

At the same time, though, the risk posed by active SETI is real. It is not obvious that all extraterrestrial civilizations will be benign - or that contact with even a benign one would not have serious repercussions for people here on Earth. There is already an agreement within the SETI community that, should a signal from beyond be picked up, various bodies will discuss what response, if any, should be sent. Yet the Valencia meeting voted against trying to set up any processes for deliberating over the style or content of any spontaneous outgoing messages. In effect, anyone with a big enough dish can appoint themselves ambassador for Earth.

The chances of active SETI causing unpleasant outcomes with today's technology are in fact remote, as this would require us to lift ourselves over the threshold of detectability for an alien civilization that just happened to be orbiting the star at which the message was aimed, or to reveal some peculiar flaw in our psychological make-up that alien 'black-ops' specialists might start working out ways to exploit. Either way, the harm, even if done at the speed of light, would take decades to arrive.

These small risks should nonetheless
"It is not obvious that all extraterrestrial civilizations will be benign, or that contact with even a benign one would not have serious repercussions." be taken seriously. When technologies offer radical new possibilities, the people who have the privilege of playing with them also have a duty to consult widely about what those possibilities might mean. The SETI community should assess them in a discussion that is open and transparent enough for outsiders to listen to and, if so moved, to actively participate. Of course, consensus may not always be possible - but the sort of debate out of which consensus has a chance to emerge must now take place. 